\title{
A autoscopia e o desenvolvimento da autonomia docente
}

The autoscopy and the development of teacher's autonomy

\author{
Diego Fogaça Carvalho ${ }^{1}$ \\ Marinez Meneghello Passos ${ }^{2}$
}

\section{Resumo}

Neste artigo trazemos resultados sobre o uso de autoscopias no processo formativo de acadêmicos da licenciatura em matemática. As autoscopias são procedimentos de coleta de informações que visam à gravação da ação do sujeito e, na continuidade, coloca-o como avaliador de seu próprio desempenho. Em função da proposta investigativa desenvolvida e das análises realizadas, compreendemos que a autoscopia pode ser caracterizada como uma oportunidade de desenvolvimento da autonomia docente, levando o futuro professor a conhecer e a questionar suas ações quando ensina matemática. Foi possível evidenciar também que esse processo fornece condições para que o licenciando se engaje em uma situação que visa à reflexão sobre sua forma de agir, e, consequentemente, à melhoria de sua prática profissional em formação.

Palavras-chave: Formação inicial de professores de matemática, autoscopia, auto-reflexão, Análise Textual Discursiva.

\begin{abstract}
In this article we bring results on the use of autoscopy in a formative process for students of a teacher education course in Mathematics. The autoscopy is a procedure of data collection that records the subject's action and puts him to observe and to analyse his performance subsequently. The interpretation of our data allowed us to figure out that autoscopy may be characterized as an opportunity for development of the autonomy of the teacher, leading the future teacher to know and question their actions when he teaches mathematics.
\end{abstract}

Keywords: Initial training of mathematics teachers, autoscopy, self-reflection, Discursive Textual Analysis.

\footnotetext{
${ }^{1}$ Universidade Estadual de Londrina - UEL | diegofocarva@gmail.com

2 Universidade Estadual de Londrina - UEL | marinezmp@sercomtel.com.br
} 


\section{Introdução}

Neste artigo apresentamos resultados de uma investigação que tem por objetivo conhecer o que estudantes do curso da Licenciatura em Matemática relataram a respeito do seu desempenho ao desenvolver uma tarefa que promoveu a auto-reflexão de sua prática docente em formação, denominada autoscopia (SADALLA; LAROCCA, 2004).

O grupo foi composto por todos os estudantes (19) matriculados na disciplina de Metodologia e Prática de Ensino - no ano de 2010 do curso de Licenciatura em Matemática de uma universidade pública do estado do Paraná.

No momento da coleta das informações, os sujeitos da pesquisa ainda não haviam realizado as observações e nem as regências nas salas de aula da Educação Básica, atividades previstas para serem cumpridas no Estágio Curricular Supervisionado. Em conformidade com o currículo do curso, é nessa disciplina que o licenciado tem a oportunidade de lecionar pela primeira vez, ou seja, assumir o papel de professor de matemática.

Todavia, cabe ressaltar que a inserção do futuro professor na escola já é promovida desde seu ingresso no curso, por meio de projetos de pesquisa e programas de iniciação à docência (PIBID). No estado do Paraná já se pode, também, após o primeiro ano da licenciatura em matemática, inscrever-se no processo seletivo simplificado - PSS - no qual o licenciado é contratado por tempo determinado para suprir alguma falta de professor do quadro próprio da rede pública de ensino.

Consequentemente, na sala de aula analisada tivemos uma diversidade de perfis de estudantes. No que diz respeito às suas experiências anteriores com a docência, alguns já deram aula em escola pública ou privada, outros trabalharam em ambos os tipos de estabelecimentos de ensino e alguns lecionaram nas séries iniciais do Ensino Fundamental, tanto na disciplina de matemática como na área de informática, música e xadrez.

A atividade desenvolvida e analisada com este grupo de licenciados denomina-se autoscopia (SADALLA; LAROCCA, 2004) e foi estruturada, nessa ocasião, da seguinte forma:

1 - Cada estudante deveria escolher um conteúdo matemático e um contexto (série e nível de ensino) em que gostaria de lecionar;

2 - Foi elaborada uma lista de apresentação e em cada dia três estudantes apresentaram as suas mini-aulas ${ }^{3}$ e os demais estudantes deveriam se colocar como alunos do nível de ensino e série indicados no início da apresentação;

3 - As aulas ministradas foram gravadas e disponibilizadas aos acadêmicos em DVD ou em seus próprios pendrives e continham não só a apresentação da aula, mas, também, a discussão realizada pela professora formadora da turma, bem como a participação dos colegas em duas situações: como aluno e outra como licenciando em matemática;

4 - Em casa, cada acadêmico deveria se assistir, analisando e avaliando seu desempenho. E, na continuidade, compor um relatório a respeito 'de como se via' nessa situação simulada de ensino e de aprendizagem.

Essas produções - os registros das autoscopias - em que os depoentes se analisam foram submetidas aos procedimentos interpretativos da Análise Textual Discursiva (MORAES; GALIAZZI, 2011), permitindo compreensões que são apresentadas no decorrer

\footnotetext{
${ }^{3}$ Uma aula de tempo menor que a realizada na escola, de aproximadamente vinte minutos.
} 
deste artigo. No entanto, anterior à análise apresentamos os referenciais teóricos que nos acompanham nesta investigação e finalizamos este documento com algumas considerações, evidenciando o que foi possível compreender deste processo em estudo.

\section{A reflexão na formação do professor: alguns destaques}

A tarefa que analisamos visou promover a auto-reflexão do licenciando para com sua prática em formação em uma situação simulada, na condição de professor de matemática. Esse fato nos colocou diante do desenvolvimento do pensamento reflexivo e de suas contribuições na futura prática do professor de matemática.

Encontra-se na literatura que as primeiras menções ao termo reflexivo são de autoria de John Dewey, mas foi com os trabalhos do norte-americano Donald Schön que essa epistemologia da prática se popularizou, provocando o que Isabel Alarcão (1996) denominou de "coqueluche contagiante".

Consultando as obras do autor, pode-se observar que sua construção teórica se opõe à epistemologia da prática que até então estava em vigência na universidade moderna ocidental e até hoje se encontra fragmentada na academia, a racionalidade técnica. Proveniente dessa posição epistemológica, tem-se instituído, segundo o mesmo autor, certa desconfiança no saber do profissional, pois a epistemologia da prática vigente até então na universidade moderna ignorava as sutilezas adjetivadas por "pantanosas da realidade", ou seja, os conflitos e as singularidades que pertencem a um caso em específico. De acordo com Schön (1987, p.17), transcender

[...] as categorias da teoria e técnica existentes, o profissional não pode tratá-lo como um problema instrumental a ser resolvido com a aplicação de uma das regras de seu estoque de conhecimento profissional. O caso não está no manual. Se ele quiser tratá-lo de forma competente, deve fazê-lo através de um tipo de improvisação, inventando e testando estratégias situacionais que ele próprio produz.

Visando à construção de uma epistemologia da prática que abarque essa necessidade acenada, Schön (1987) propõe uma formação profissional centrada na prática, que visa promover um atributo por ele designado de artistry, essa competência artística influenciaria na maneira de agir desses profissionais em situações práticas que, inúmeras vezes, são conflituosas, únicas e incertas. Em suma, extrapolam o que por ele já é conhecido. Alarcão (1996) afirma que:

Essa competência [artistry], que Ihes permite agir no indeterminado, assenta num conhecimento tácito que nem sempre são capazes de descrever, mas que está presente na sua actuação mesmo que não tenha sido pensado previamente; é um conhecimento inerente e simultâneo às suas ações e completa o conhecimento que Ihes vem da ciência e das técnicas que também dominam. (ALARCÃO, 1996, p.16)

Porém, antes de propor uma formação que favoreça o desenvolvimento desta especificidade, o artistry, Schön apresenta o modo como vê a construção de conhecimento na prática dos profissionais, indo ao encontro do modo como a racionalidade técnica aborda esses mesmos sujeitos (em resumo) - "executores de técnicas". 
Inerente à prática profissional, tem-se a construção de conhecimentos relacionados ao fazer. Esses conhecimentos ficaram então conhecidos pela designação de Polanyi por conhecimento tácito:

Espontâneo, intuitivo, experimental, conhecimento quotidiano, do tipo revelado pela criança que faz um bom jogo de basquetebol, que arranja uma bicicleta ou uma motocicleta ou que toca ritmos complicados no tambor, apesar de não saber fazer operações aritméticas elementares. (SCHÖN, 1997, p.82)

Essa forma de conhecimento que surge da ação na realidade, e que muitas vezes é complicado de ser justificado por quem o realiza, Schön (1987) denominou por conhecimento na ação:

Usarei a expressão conhecer-na-ação para referir-me aos tipos de conhecimentos que revelamos em nossas ações inteligentes performances físicas, publicamente observáveis, como andar de bicicleta, ou operações privadas, como a análise instantânea de uma folha de balanço. (SCHÖN, 1987, p.31)

Conhecer na ação é um processo tácito, que se coloca espontaneamente, sem deliberação consciente e que funciona, proporcionando os resultados pretendidos enquanto a situação estiver dentro dos limites do que aprendemos a tratar como normal. (SCHÖN, 1987, p.33)

Todavia, esse conhecimento produzido na prática é também caracterizado por ser limitado. Há situações em que o repertório de conhecimentos na ação não dá condições para a situação problemática identificada, o que chama de surpresas da prática. É nesse ponto que o autor conceitua a reflexão-na-ação. Ao se deparar com uma situação anormal, durante a ação, o profissional pensa a respeito do fato identificado, almejando sua solução. Diante deste contexto é que se tem uma situação propensa para que o profissional se valha doartistrypara sua tomada de decisão.

Ao aprofundar sua compreensão da reflexão-na-ação, Schön (1987) ressalta que, ao se engajar nesse processo de reflexão, o profissional leva em consideração o evento inesperado e o processo de conhecer-na-ação que o levou até a situação. Compreende-se que a atitude engloba tanto o fenômeno como o próprio sujeito, principalmente o modo como conhece e procede em sua ação profissional.

A reflexão também apresenta um viés crítico da estrutura e dos pressupostos do ato de conhecer na ação, ou seja, "Pensamos criticamente sobre o pensamento que nos levou a essa situação difícil ou essa oportunidade e podemos, neste processo, reestruturar as estratégias da ação, as compreensões do fenômeno ou as formas de conceber os problemas" (SCHÖN, 1987, p.33). Enfim, a reflexão-na-ação gera o experimento imediato, ou seja, após pensar a respeito da surpresa inicial, o profissional tem a oportunidade de colocar em prática o que pensou, avaliando e realizando ajustes caso considere necessário.

No entanto, o sujeito pode, em outro momento, realizar uma construção da realidade por ele vivida durante a prática que ainda o mantém intrigado, em um movimento retrospectivo. Tem-se, então, neste caso, uma reflexão sobre a ação. Segundo Schön (1997, p.83) "Após a aula, o professor pode pensar no que aconteceu, no que observou, no significado que the deu e na eventual adoção de outros sentidos. Refletir sobre a reflexãona-ação é uma ação, uma observação e uma descrição, que exige o uso de palavras". 
E em outros momentos, pode-se considerar também outro nível de reflexão que extrapola os citados anteriormente, a reflexão sobre a reflexão-na-ação. Alarcão (1996) considera que esse processo permite ao sujeito progredir em seu desenvolvimento profissional e construir uma forma pessoal de conhecer, contribuindo com a determinação de ações futuras, com a compreensão de futuros problemas e com a descoberta de novas soluções.

De forma resumida, trouxemos alguns destaques da teoria de Donald Schön, muitas vezes adjetivada por reflexiva e está relacionada ao atributo de pensar sobre os fatos e de valer-se do artistry para a tomada de decisões.

Com relação à formação do profissional, Schön acena para a construção de espaços em que seja possível levar os futuros profissionais a desenvolverem o artistry desde o início da formação. O autor designa esses espaços de mundo virtual em que se tem uma representação da prática. Todavia, nesses contextos o peso do erro do aprendiz é bem menor do que na realidade.Tem-se, também, a oportunidade de voltar atrás, ver o que foi feito, buscar aprimoramento, sendo assistido por um tutor, ou supervisor, que tem a função de contribuir com o aprendiz, mostrando suas deficiências e focando o ensino da prática. Essa situação pode ser compreendida como uma inserção do aprendiz em uma comunidade profissional, pois, segundo Schön (1987, p.39):

Quando alguém aprende uma prática, é iniciado nas tradições de uma comunidade de profissionais que exercem aquela prática e no mundo prático que eles habitam. Aprende suas convenções, seus limites, suas linguagens e seus sistemas apreciativos, seu repertório de modelos, seus conhecimentos sistemáticos e seus padrões para o processo de conhecerna-ação.

Diante deste quadro teórico, vemos que a autoscopia se configurou como um mundo virtual possibilitando ao sujeito refletir sobre a sua ação. A captura em vídeo da aula trouxe ao licenciando as ações, por ele realizadas durante a aula, oportunizando uma reflexão a respeito do conhecimento na ação.

Vê-se aqui instituída uma oportunidade de aprendizagem da docência que pode levar acadêmicos a se engajarem em uma prática intelectual, visando sanar os problemas por eles identificados.

\section{Procedimentos metodológicos}

Para a interpretação das informações coletadas em função desta investigação, utilizamos a Análise Textual Discursiva (MORAES; GALIAZZI, 2011). Justificamos sua adoção pela necessidade de avanço na interpretação das descrições para a constituição de um metatexto que nos levasse a compreensões do fenômeno em questão.

Os procedimentos analíticos apresentados pela Análise Textual Discursiva pautam-se, em síntese, em dois movimentos: um que visa desconstruir e outro reconstruir. Diante das informações obtidas, consideradas representativas do fenômeno que se destina analisar neste caso os relatórios dos licenciandos a respeito das mini-aulas por eles ministradas -, e que constituem o corpus da pesquisa, ou seja, o conjunto de documentos que será submetido aos procedimentos de análise (BARDIN, 2004, p.90), foi realizado esse processo interpretativo de que trazemos algumas conclusões.

A primeira ação desenvolvida é a de conhecer o que se tem em mãos por meio da leitura flutuante. Essa primeira leitura precisa ser desprovida de intenções de pesquisa, o 
pesquisador deve estar aberto para várias compreensões do mesmo conjunto de dados. Pode-

-se caracterizá-la por uma leitura descompromissada.

Após esse primeiro contato com o corpus, dá-se início ao processo de unitarização, que visa fragmentar as informações, evidenciando as unidades de registro. Para facilitar o regresso das unidades de registro aos documentos originais, faz-se necessária a construção de códigos, que no nosso caso são compostos por combinações entre algarismos indoarábicos, romanos e letras do alfabeto.

O próximo movimento, denominado por categorização, inicia-se por meio do estabelecimento de outra organização. Segundo Moraes e Galiazzi (2011, p.22-26), esse procedimento analítico pode ser realizado de quatro maneiras diferentes: a dedutiva; a indutiva; a dedutiva-indutiva; e intuitiva. Optamos por utilizar a categorização indutiva, aquela em que as categorias emergem dos dados, ou seja, a construção categorial se dá por meio de um processo de leitura e acomodação por semelhança de sentido ${ }^{4}$. Inicialmente, as categorias estranham-se aos olhos, porém, diante de várias retomadas e refinamento dos critérios utilizados, as categorias começaram a apresentar contornos. Todavia, os contornos por nós construídos estão suscetíveis a mudanças, ou seja, a cada retomada dos dados e a cada aprofundamento realizado, tende-se a obter uma estruturação outra com compreensões diferenciadas. Pensamos nesse caso que a cada movimento nos aproximamos cada vez mais do fenômeno investigado.

Passa-se, então, à comunicação dos achados. A essa fase, segundo os autores, dá-se o nome de captar o novo emergente e tem a finalidade de produção de um metatexto.

Os metatextos têm por autoria o pesquisador e consistem da sua visão do fenômeno analisado. Nessa fase, as categorias são tomadas como sua estrutura. Nesse sentido, construímos para cada uma das categorias pequenos textos que visaram em um primeiro momento sua descrição. Todavia, de posse dos fichamentos dos textos lidos fomos, concomitantemente, procurando por ideias que se aproximavam das descrições. Esse movimento permitiu avançar na compreensão daquilo que os licenciandos apontavam na autoscopia, culminando na escrita de outros textos. Por fim, elaboramos outros parágrafos que tiveram a função de unir as categorias, compostos por elementos aglutinadores que se pautaram na nossa interpretação, bem como no referencial teórico estudado.

Na sequência, apresentamos os resultados advindos do movimento descrito anteriormente. Todavia, pensamos que é necessário ressaltar que o movimento analítico eleito para a composição do trabalho não é finito. Os dados e os referenciais atingiram até o momento certa acomodação, porém, cremos que em outro momento será possível retomar essas informações e construir outras compreensões.

\footnotetext{
${ }^{4}$ Estamos considerando aqui, à maneira como o faz Vygotsky, que enquanto o significado consiste em um núcleo relativamente estável de compreensão da palavra, compartilhado por um grupo grande de pessoas, o sentido é particular, dependente do contexto do uso da palavra e remete às vivências afetivas do indivíduo, ou seja: o sentido da palavra liga seu significado objetivo ao contexto de uso da lingua e aos motivos afetivos e pessoais de seus usuários (OLIVEIRA, 1993, p.50).
} 


\section{Análises e considerações}

A tarefa submetida à análise levou os futuros professores de matemática a refletirem e realizarem remissões a respeito da sua prática profissional em formação, colocando-os na posição de seu próprio aluno.

Para ficar mais evidente a forma com que organizamos nosso olhar sobre essas autoscopias, destacamos que consideramos unidades de contexto e unidades de registro. As unidades de contexto estão relacionadas à ação de assistir ao próprio vídeo e às remissões realizadas sobre ele - na autoscopia. Neste caso, temos duas configurações de Contextos 01 e 02.

Quando as remissões são relativas a declarações que vão além do que foi visto no vídeo, por exemplo, comentários referentes a sensações provocadas ao ver-se ministrando uma aula, comparações com relação a intenções que possuía e que durante a aula não se realizaram, temos o que denominamos de Contexto 01 . Contudo, se os relatos não assumem essa especificidade, ou seja, quando os depoentes fazem referência a situações específicas presentes no vídeo, tem-se o que denominamos de Contexto 02. No Quadro 1 podemos observar o que foi descrito neste parágrafo, porém outras informações também são apresentadas e dizem respeito ao modo como o conteúdo relativo ao contexto foi estruturado pelo depoente.

Como pode ser observado no Contexto 01, identificamos: comentários (01.a) e comparações (01.b). No caso dos comentários, são considerados os relatos que comunicam um fato, e cuja frase traz uma afirmação. Para o subgrupo (01.b), consideramos os depoimentos em que o acadêmico se vale de comparações entre situações vivenciadas ou imaginadas.

Para o Contexto 02, temos também dois subgrupos. Contudo, um deles ainda traz mais dois subgrupos adjacentes. Como pode ser observado (02.a), nos remete a relatos em que o entrevistado identifica e se posiciona a respeito de procedimentos adotados durante a mini-aula e que podem ser considerados como falhos (02.a.1) ou bons (02.a.2). Nos momentos em que as falas dizem respeito a sugestões que poderiam corrigir situações consideradas inadequadas temos o subgrupo (02.b), que não traz subgrupos adjacentes.

Quadro 01 - Unidades de Contexto

\begin{tabular}{|c|c|c|c|}
\hline Contextos & Unidades de Contexto & $\begin{array}{c}\text { Subgrupos das unidades } \\
\text { de contexto }\end{array}$ & $\begin{array}{l}\text { Subgrupos dos } \\
\text { subgrupos de contexto }\end{array}$ \\
\hline \multirow[t]{2}{*}{ Contexto 01} & \multirow{2}{*}{$\begin{array}{l}\text { Vão além do procedimento } \\
\text { gravado durante a } \\
\text { realização da mini-aula. }\end{array}$} & 01.a) Comentários. & \\
\hline & & 01.b) Comparações. & \\
\hline \multirow[t]{3}{*}{ Contexto 02} & \multirow{3}{*}{$\begin{array}{l}\text { Tem como foco o } \\
\text { procedimento gravado } \\
\text { durante a realização da } \\
\text { mini-aula. }\end{array}$} & \multirow{2}{*}{$\begin{array}{l}\text { 02.a) Identificação e } \\
\text { posicionamento a } \\
\text { respeito de } \\
\text { procedimentos } \\
\text { adotados durante a } \\
\text { mini-aula. }\end{array}$} & $\begin{array}{l}\text { 02.a.1) Procedimentos } \\
\text { avaliados como falhos. }\end{array}$ \\
\hline & & & $\begin{array}{l}\text { 02.a.2) Procedimentos } \\
\text { avaliados como bons. }\end{array}$ \\
\hline & & $\begin{array}{l}\text { 02.b) Sugestões de } \\
\text { correção para situações } \\
\text { consideradas } \\
\text { inadequadas. }\end{array}$ & \\
\hline
\end{tabular}

Fonte: Os autores. 
Cabe lembrar, neste momento, que estes contextos e subgrupos surgiram das interpretações dos depoimentos dos acadêmicos, ou seja, são agrupamentos emergentes das informações coletadas. Eles são fruto de leituras e releituras das autoscopias e de algumas conversas que tivemos com os depoentes, para a compreensão dos registros presentes nos relatórios que denominamos 'autoscopias'. A subdivisão em unidades de contexto e a construção de categorias relacionadas a esses contextos - que serão apresentadas no Quadro 2 - fazem parte de um movimento interpretativo, possibilitado pela Análise Textual Discursiva e pela sua proposição de construção de categorias que auxiliem na comunicação do que foi compreendido do fenômeno sob investigação.

De posse dos contextos que emergiram e dos agrupamentos que eles nos possibilitaram, optamos por focar o assunto que estava presente nessas unidades de registro alocadas em cada agrupamento.

A leitura - em bloco - desses grupos de relatos nos permitiu interpretar novamente o que havíamos aproximado, via acomodação dos contextos, e construir algumas categorias que nos remetiam ao assunto em pauta nos fragmentos da autoscopia de cada estudante. No Quadro 02, trazemos a categorização segundo cada contexto descrito anteriormente.

Quadro 02: Conjunto de Categorias

\begin{tabular}{|l|}
\hline \multicolumn{1}{|c|}{ Categorias de cada contexto } \\
\hline \multicolumn{1}{|c|}{ Contexto 01} \\
\hline i) A atividade na sua formação. \\
\hline ii) Estranhamento. \\
\hline iii) Autoavaliação. \\
\hline iv) Comparação entre a intenção da mini-aula e o que desenvolveu. \\
\hline v) Comparã̃o entre as açães que desenvolveu na mini-aula e uma situação real em sala de aula. \\
\hline \multicolumn{2}{|c|}{} \\
\hline I) Segurança. \\
\hline II) Fala. \\
\hline III) Escrita. \\
\hline IV) Gestão do tempo da aula. \\
\hline V) Exposição do conteúdo matemático. \\
\hline VI) Planejamento da aula. \\
\hline VII) Postura. \\
\hline VIII) Relação professor-aluno.
\end{tabular}

Fonte: Os autores.

Com relação às categorias relacionadas ao Contexto 01 , podemos esclarecer que são relativas a comentários (01.a) que se limitaram a falar: (i) Do papel da atividade (realização da mini-aula) na formação do licenciado como professor de matemática; (ii) Do desempenho que julgam ter tido na realização da mini-aula em uma situação de autoavaliação; (iii) de uma sensação de estranhamento de se ver no vídeo. No que diz respeito às comparações (01.b), os registros abordavam: (iv) As intenções do licenciado para com a mini-aula e o que foi gravado; (v) As ações desenvolvidas durante a mini-aula em uma situação real de sala de aula.

Como pode ser observado - as categorias: a atividade na sua formação, estranhamento e autoavaliação, estão relacionadas ao subgrupo comentários do Contexto 01 e as categorias (iv) e (v) encontram-se relacionadas ao subgrupo comparações deste mesmo contexto. 
Com relação às categorias emergentes dos registros acomodados no grupo do Contexto 02, a subdivisão não ficou tão delimitada desta forma, isto é, há categorias comuns para subgrupos distintos. Esclarecemos: tanto no subgrupo (02.b) quanto nos subgrupos (02.a.1) e (02.a.2), os assuntos identificados foram: Segurança; Fala; Escrita e sua organização na lousa; Gestão do tempo disponível da aula; Exposição do conteúdo matemático; Planejamento da aula; Postura; Relação professor-aluno. A única exceção foi que em (02.a.2) não temos qualquer remissão com relação à categoria (I) - Segurança.

O que temos até o momento - deste movimento investigativo - são os pareceres dos estudantes da Licenciatura em Matemática a respeito da realização de uma mini-aula seguida de autoscopia, acomodados em dois grandes grupos - os contextos - quando focam especificamente o vídeo da mini-aula e quando vão além do vídeo. Para esses dois contextos foi possível evidenciar em suas colocações a relação da atividade com o processo formativo em que estão inseridos, a estranheza com relação a se ver no vídeo, a visão da atividade como uma proposta autoavaliativa, o levantamento das intenções e sua comparação com o que foi desenvolvido, a construção de uma reflexão entre a ação desenvolvida e a realidade de uma sala de aula, e, ainda, questões relativas à segurança, à fala, à escrita, à gestão do tempo de aula, à exposição do conteúdo, ao planejamento da aula, à postura e, por fim, à relação professor-aluno. Se tivéssemos que construir nossa argumentação a respeito da proposição da realização de mini-aulas seguida de autoscopia para os acadêmicos da Licenciatura em Matemática, destacaríamos esses elementos como producentes e estruturantes para sua justificação.

Contudo, uma análise dos dados mais verticalizada se coloca como possível e são essas considerações outras que apresentamos na continuidade deste artigo. Para tal apresentação, vamos construir as argumentações da mesma forma com que as unidades de pesquisa foram emergindo diante dos procedimentos da Análise Textual Discursiva.

\section{Sobre o Contexto 01- algumas considerações}

Situados neste contexto, a primeira distinção identificada faz referência à natureza das afirmações manifestadas pelos depoentes: os comentários e as comparações.

Os comentários possuem em comum o desprendimento do fato específico realizado na mini-aula, colocando em cena outras situações, entre elas: falar sobre o papel da atividade desenvolvida em sua formação de professor de matemática, realizar uma autoavaliação da sua atuação na condição de ser seu próprio aluno, falar a respeito da sensação de estranhamento ao realizar a atividade; são os assuntos abordados pelos comentários pertencentes a esse contexto.

A outra parcela de unidades de pesquisa traz em sua estrutura comparações. Nesse caso, têm-se dois contextos que são cotejados, em que se visa localizar suas divergências e convergências. Os assuntos identificados abordam o impacto de algumas ações desenvolvidas na mini-aula em uma situação real de sala de aula, bem como uma comparação entre as intenções elaboradas para a mini-aula e o que foi realizado pelo licenciando.

O primeiro assunto identificado e denominado por categoria (i) acomoda comentários realizados pelos licenciados a respeito dos efeitos por eles identificados provenientes da realização da atividade em sua formação profissional. Essa categoria acomoda falas de cinco depoentes, isto é, menos da metade dos acadêmicos pensou a respeito da atividade em sua prática profissional ou a relacionou com o processo formativo de que participa. Conforme é apresentado por Sadalla e Larocca (2004), o processo de autoscopia se 
constitui como uma alternativa metodológica para uma formação de professores que se centra nas ideias do professor reflexivo e na prática reflexiva. Encontramos nas falas dos licenciados que a autoscopia trouxe elementos relativos à prática profissional que antes passavam despercebidos ( $\mathrm{A05}$; ; A06 e A17). O depoente A05, diferentemente dos demais, que falam de forma geral, especifica quais seriam esses elementos:

Observando minha mini-aula, me deparei com inúmeras coisas que nem imaginava que eu fazia quando estava dando uma aula, minha fala, postura e gesticulação, que muitas vezes por mim passavam despercebidas, e pude ver com o olho do aluno como era minha forma de dar aula. (A05)

Para A19 e A05, a situação não só oportunizou se conhecer, como futuro professor, mas, também, colocou em evidência uma situação que os levou a pensar e a procurar a melhor solução para as ações por eles identificadas e classificadas como "falhas". Nessas falas, já se percebe de forma mais clara o engajamento do licenciando na busca para solucionar o que foi conceituado como problemático para sua futura prática profissional.

[...] gostei muito da experiência, pois pude refletir sobre minha postura e assim tentar achar o melhor caminho para que possa melhorar cada dia mais minhas aulas e nunca achar que estou pronto ou que sei de tudo mesmo que vou dar aulas para quem esteja vendo pela primeira vez o conteúdo ministrado. (A19)

Neste contexto e categoria, temos também o depoimento do licenciado A10, que simplesmente adjetiva a atividade como importante, sem justificativas.

Diante dessas considerações, podemos destacar que a autoscopia coloca-se como uma oportunidade de aprendizagem da prática docente, que promove a autonomia do futuro professor que se dispõe a solucionar os problemas evidenciados em sua prática na sala de aula e que foram considerados inadequados.

A segunda categoria (ii) - estranhamento - focaliza uma situação pessoal vivenciada pelos licenciandos, no momento em que cada um se assistiu dando aula. Conforme é apresentado por Sadalla e Larocca (2004), é comum, em situações de autoscopias, que "apareçam atitudes elusivas, de não identificação ou rejeição, como recusa em se rever, atitudes depressivas ou agressivas, atrasos ou ausências, partidas súbitas, entre outras manifestações defensivas por parte do sujeito" (SADALLA; LAROCCA, 2004, p.424). Nessa categoria, foram alocados os depoimentos de: A06 e A19 - que usaram a palavra "estranhamento" em seus registros; A17, que denominou a situação por constrangimento; A10, que a denominou de "certo mal-estar"; A17 sentiu-se "entristecido"; e, por fim, A19 que se mostrou "surpreso" ao ver-se ministrando uma aula. Em um depoimento complementar, A17 relata que após alguns minutos de visualização de sua mini-aula, a sensação de "constrangimento" dá lugar ao "entristecimento", mas mesmo assim ele conseguiu realizar sua autoscopia, construindo uma "análise crítica" de sua atuação como professor.

A respeito do modo como o vídeo foi assistido, somente o depoente A19 menciona ter sido devagar, pausando o vídeo em alguns momentos. E ele justifica sua atitude,

\footnotetext{
${ }^{5}$ Cada um dos acadêmicos do curso de Licenciatura em Matemática recebeu um código, este é um exemplo, acadêmico A de número 05 - A05.
} 
mostrando-

-se envergonhado com a aula ministrada, pois se imaginava lecionando de outra maneira, muito melhor.

Na categoria (iii), estão acomodadas as unidades de registro em que os depoimentos dizem respeito ao desempenho nas mini-aulas. As autoavaliações (nome que demos a esta categoria) são de dois tipos - aquelas que indicam que o desempenho foi ruim (A17, A05, A04); e aquelas que dizem ter sido mediano (A12, A09 e A07). Contudo, os depoentes não justificam suas adjetivações, mas complementam que a atividade de autoscopia contribuiu para que eles tomassem consciência de suas deficiências na prática de sala de aula. Destacamos a seguir alguns depoimentos que elucidam essas considerações:

Comecei a assistir a gravação e tive a noção real de que o que havia feito tinha sido muito ruim. (A17)

Não consigo achar/detectar nenhum ponto positivo em minha mini-aula a não ser a coragem de ir à frente e tentar apresentar algo. (A04)

[...] já comecei a pensar sobre tudo que havia feito durante a apresentação. (A17)

[...] a possibilidade de em uma próxima mini-aula eu tentar me esforçar mais para conseguir fazer algo no mínimo 'descente'. (A04)

[...] vou tentar corrigir os defeitos no futuro. (A12)

Com relação a esse mesmo Contexto 01- que apresenta destaques que não se restringem aos fatos específicos gravados em vídeo - podemos analisar agora as situações que se sustentam em comparações, ou seja, nas falas dos depoentes foi possível evidenciar uma relação entre a situação vivenciada pelo licenciando e suas intenções (em geral, não atingidas) ou, então, uma alusão à realidade da sala de aula, propriamente dita.

$\mathrm{Na}$ categoria (iv) acomodamos as falas que relacionam o ocorrido e as intenções - nela temos os depoimentos de A17 e A04. Alguns fragmentos do que analisamos podem ser observados a seguir:

O que posso dizer é que eu estava de fato envolvido com a situação, queria estar ali, sendo professor e que procurei fazer o melhor. Eu, de fato, havia preparado uma aula e tentei segui-la, apesar de não tê-la preparado adequadamente para a situação. (A17)

Neste modelo de tentativa frustrada de Resolução de Problemas, queria propor o problema e deixar a sala quebrar a cabeça, até que eu entrasse com uma questão-problema mais simples e/ou o conceito detalhado das propriedades que envolvem potenciação em seu cerco geral. (A04)

A17 demonstra ter se dedicado à realização da mini-aula, indicando que tinha boas intenções, pois procurou fazer o melhor. Mostra, também, que preparou a aula e tentou seguir seu planejamento. Todavia, após ver a sua ação no vídeo, chegou à conclusão de que não preparou a aula adequadamente para um sétimo ano do Ensino Fundamental. Quanto ao A04, ele afirma que sua intenção para com a mini-aula foi bem diferente do que ele desenvolveu. Segundo o depoente, sua intenção era de constituir um ambiente de aprendizagem fundamentado na resolução de problemas. Porém, na realização da miniaula, ele não conseguiu colocar em prática o que havia planejado. 
Na última categoria, (v), deste contexto, trazemos aqueles depoimentos que realizam a comparação do que ocorreu durante a mini-aula e uma situação real de sala de aula. Cabe ressaltar que a mini-aula se constitui em um ambiente de simulação da prática docente, é um "faz de conta" que visa o autoconhecimento do futuro professor de sua prática profissional em formação. A12 ressalta que se estivesse em uma sala de aula da Educação Básica exploraria o conteúdo matemático por ele planejado de um modo diferente. Em sua mini-aula, ao apresentar o algoritmo da operação de subtração, valeu-se do termo "empresta" e "transforma", o modo como desencadeou a discussão a respeito do uso dessas palavras o fez chegar à conclusão de que agiu como um "cabeça-dura", ou seja, que se comportou como uma pessoa que não aceita os conselhos e opiniões de outros. Todavia, se ele estivesse em sala de aula, afirma que teria realizado a introdução desses termos de outro modo.

Pouco antes de terminar a aula fiz um comentário no tocante aos termos matemáticos empresta e transforma: "sinceramente, eu prefiro falar empresta" soou como se eu fosse um "cabeça dura" perante a discussão, na verdade, em sala de aula eu só falaria o termo empresta depois de esclarecido todo o contexto matemático por trás da palavra e com a garantia de que os alunos tivessem entendido, usando apalavra "empresta" como se fosse um resumo da teoria. (A12)

Outra situação abordada nessa categoria diz respeito aos momentos em que A17 permaneceu em silêncio, escrevendo na lousa ou de costas para a turma e os longos momentos em que ficou em silêncio frente à turma. Segundo ele, esses momentos, em uma situação real de sala de aula, seriam o suficiente para ele perder o controle da turma.

O tempo que gastei somente para escrever o problema no quadro sem falar nada, somente lendo o problema em alguns momentos, era suficiente para o caos na sala de aula. [...] Notei também que fiquei mais em silêncio do que falei e imaginei que numa situação normal eu estaria encrencado se continuasse daquele jeito. (A17)

Para A06, a situação vivenciada em uma situação real de sala de aula configura-se como "não boa", quando ele se "viu no vídeo errando a resolução de um exercício".

A16 relata ter se sentido muito nervoso. Porém, enfatiza que "um dos culpados por seu nervosismo foi a câmera" que o estava filmando e, justifica, "em uma situação real de sala de aula não teríamos a câmera" e quanto ao fato de ter se "perdido na resolução do exercício", afirma que o procedimento que adotaria era o de regressar ao início da questão, ou se fosse uma questão que não soubesse resolver, diria que iria pesquisar e em outro momento traria a atividade novamente para os seus alunos. Segundo ele, essa situação "aconteceria de forma tranquila", diferentemente do que ocorreu durante a gravação do vídeo para a realização de autoscopia.

\section{Sobre o Contexto 02 - algumas considerações}

As unidades de análise acomodadas no Contexto 02 possuem em comum a referência às ações observadas no vídeo. Nesses casos, o licenciando identifica, conceitua e, em alguns casos, traz uma sugestão de ratificação daquilo que observou como inadequado.

Como descrito no Quadro 01, podemos acomodar o que será apresentado na sequência em dois grandes grupos - separados pelo que nominamos de contexto. Um em que há o posicionamento do licenciando em relação às suas ações durante a mini-aula - 
conceituando-a como falha ou não; e outra em que ele reconstrói a situação vivida sugerindo saídas para o que analisou. É evidente que há uma distinção de sentido com relação a essas duas acomodações, contudo, neste artigo não analisaremos esses dois subgrupos de contextos distintamente, por questão de espaço na composição do artigo e também pelo fato de que as conclusões a que chegaríamos, construindo os dois caminhos interpretativos, estariam muito próximas uma da outra, em função da análise que viemos realizando. Contudo, em Carvalho (2012), é possível encontrar diversas informações complementares a respeito desta situação investigada.

Assim como fizemos com relação ao Contexto 01, vamos discutir e apresentar nossas considerações, categoria por categoria, para este Contexto 02.

I - Segurança: Nesta situação em análise, o termo 'segurança' está relacionado ao estado emocional do licenciando frente à realização da atividade. A falta de segurança vem acompanhada pela sensação de medo e despreparo. O sujeito se sente ansioso e pode apresentar suor excessivo, dor de cabeça, dor de estômago, gagueira, dentre outros sintomas. Cabe destacar que todos esses adjetivos, descritos na frase anterior, foram retirados das autoscopias dos acadêmicos que colaboraram com esta pesquisa.

A09 destaca que se intimidou devido ao grupo de alunos fictícios serem os colegas do curso de licenciatura. Para o depoente, nesse contexto ele se encontrava no mesmo patamar que seus companheiros de classe e diz ser complicado falar de um assunto que todos ali conheciam, pois durante todo o tempo da mini-aula esteve preocupado com possíveis deslizes.

Percebo que minha postura era de muita insegurança, onde realmente estava inseguro, pois acho muito complicado falar um assunto dominado por todos os que estavam ali assistindo, e realmente a tensão de não poder dar nenhum deslize é grande. (A09)

Como podemos observar, a atividade da mini-aula coloca-se como uma situação desconfortante para A09, principalmente pelo fato de ele não querer errar na frente de seus colegas de turma.

Os licenciandos A07 e A23 já se valem de outra justificativa, em ambos os casos foi o medo de não ser compreendido pela turma de alunos fictícios o fator que desencadeou a sensação de insegurança. A07 mostra que seu medo estava relacionado ao enunciado da questão que ele mesmo trouxe para sua mini-aula. A23 cita que o medo de não ser compreendido tomou conta dele por toda a apresentação da mini-aula, ele ficou "com muito medo de explicar algo errado" e, devido ao seu nervosismo, acabou apresentando a mini-aula diferente do que tinha planejado.

A15 aponta diversos "defeitos" em sua atividade e, com relação a essa categoria, ressalta que sua maior falha "foi a falta de confiança" em si. E argumenta:

[...] tenho que melhorar minha conduta quando estiver na frente das pessoas, gostaria que a professora me ajudasse a perder pelo menos 0 medo. (A15)

Outros três depoentes - A06, A03 e A01 - destacam que estavam nervosos e esse foi um fator que os prejudicou no desenvolvimento da mini-aula. A06 relata ter se esquecido de como finalizar a questão, situação por ele caracterizada por "deu um branco" (A06); A01 fala do nervosismo de um modo diferente, apressou-se demais na aula, dando risadinhas discretas que vêm a caracterizar o modo como lida nesse tipo de situação. Segundo o 
licenciando "[...] vou fazer rápido, pra terminar logo com isso" (A01), todavia, após analisar o vídeo, afirma que poderia ter apresentado a mini-aula com mais calma.

Com relação à categoria - Segurança - apresentamos anteriormente as colocações de sete depoentes, que poderiam ser acomodadas no subgrupo (02.a.1), contudo, outros três depoentes - A08, A15 e A23 - (sem considerarmos a exclusão mútua, isto é, podem ter relatos sobre uma mesma categoria acomodados em subgrupos distintos) tratam da questão 'segurança' de outra forma (o que nos levaria a acomodá-los no subgrupo (02.b) A15 e A23 repetidamente), neste caso sugerindo a superação da insegurança e do medo como um passo inicial para ser professor: "[...] espero poder superar esse medo, pois terei que estar preparado para encarar uma sala de aula" (A08).

II - Fala: O segundo 'assunto' evidenciado nas autoscopias e que, posteriormente, o constituímos como categoria, foi a remissão à forma de falar, ao jeito de falar em sala de aula, e à visão que tiveram de considerar a fala como um recurso importante durante a realização de uma aula.

Em resumo, eles destacam nesta categoria o "tom de voz baixo"; "sons repetitivos que sobrecarregam a fala, dificultando a compreensão do que fala"; "O vocabulário limitado"; "o uso de linguagem inapropriada para a idade dos alunos". Porém, cabe destacar que não tivemos somente colocações negativas, houve aqueles que disseram:"gostei da minha dicção"; "mantive a fala adequada durante toda a aula".

Além desses depoimentos que levantam as falhas e indicam os acertos, temos também nesta categoria aqueles que sugerem esse tópico como importante de ser observado e regulado por quem está pretendendo ser professor - com relação a esta forma de abordagem nos depoimentos pudemos evidenciar cinco sugestões: "é preciso melhorar e ampliar o vocabulário"; "para ser professor tem que melhorar o modo de falar de uma maneira geral"; "é necessário reduzir os vícios de linguagem"; "temos que aumentar o tom de voz", "falar mais constantemente durante a aula, o tempo todo temos que estar falando".

A seguir foram incluídos alguns relatos dos acadêmicos que podem exemplificar as colocações relativas a esta categoria.

[...] pude notar (ou melhor, confirmar) o que todos já me diziam (e dizem): minha voz é muito baixa. (A13)

A comunicação verbal foi sem dúvida a pior parte, agora eu vi como sou confuso ao falar [...] o áudio aqui em casa está meio ruim, mas o meu português, as minhas explicaç̃̃es (sim, expliquei, mas não saiu como eu imaginava que tinha saído).(A10)

[...] com relação a essa parte de falar, vou me corrigir, até conversando com os amigos. (A10)

Em vez de você, eu falava cê. (A02)

Tenho que parar de falar né e errrrrr, ficou muito esquisito. (A12)

Eu falei muitas vezes, tudo certo? Estão entendendo? (A16)

Penso que se falasse um pouco mais alto e constante, a aula já teria melhorado bastante. (A17)

[...] explicar melhor o que se está pensando. (A08) 
[...] com vocabulário pobre a aula fica muito repetitiva e cansativa. (A05)

[...] para ser professor tem que procurar melhorar a sua fala. (A03)

Durante o desenvolvimento do exercício, se estivesse um pouco mais calmo, sem tanta pressa, eu poderia ter elaborado melhor as palavras na hora de explicar. (A01)

III - Escrita: Pode-se compreender, mediante a análise do que apresentam na autoscopia, que a atividade proposta permitiu aos licenciandos um primeiro contato com sua caligrafia em uma situação em que escreveram para o outro e não para si mesmos. Cabe destacar que a professora proponente da atividade, antes de finalizar a filmagem e mesmo durante a apresentação do licenciando de sua mini-aula, tomava o cuidado de gravar tudo o que estava colocado na lousa, focando-a em zoom, em diversos momentos.

Percebe-se que essa situação desencadeou algumas críticas e surpresas que acenam para um autoconhecimento das potencialidades e deficiências do modo como se expressam, gerando sugestões de superação das falhas identificadas. Vê-se que a busca por uma lousa que respeite uma lógica sequencial organizada e que possua uma caligrafia no mínimo legível com desenhos compostos por linhas retas; algo almejado pelos futuros professores para suas práticas profissionais em formação, em que se visa facilitar o acesso dos alunos ao conteúdo matemático representado na lousa. A escrita e sua organização na lousa junto à fala do professor são recursos indispensáveis (fato apontado por eles em seus depoimentos) para que haja comunicação em sala de aula e, consequentemente, acesso ao conteúdo matemático, configurando um ambiente para a aprendizagem. Nesse sentido (os acadêmicos) destacam que desenvolver ou aperfeiçoar o modo de escrever e organizar a escrita na lousa se refere a conhecimentos básicos para uma formação inicial de professores de matemática, principalmente no que diz respeito à gestão do conteúdo.

E minha forma de usar o quadro também não gostei, vendo depois, [percebo que] ficou confusa, a parte de ir fazer a conta e voltar, deixou meio estranha a compreensão.(A10)

[...] vendo o vídeo, acho que fica melhor continuar sempre em frente sem ir e voltando no uso da lousa. (A10)

Ser mais organizada na forma que escrevo no quadro para que meus alunos não se percam. (A16)

Outro fato que percebi é quanto à minha letra. Sempre que vou escrever no quadro, fico preocupado em escrever rápido, já que outras pessoas estão esperando por mim. Devido a isso, 'aperto os passos' e o resultado é o que se pode observar no quadro: 'um monte de rabiscos'. (A13)

Agora falarei da minha letra, foi a única coisa que fui melhor que eu pensava, não que minha letra agradou, ao contrário, achei ela horrível, mas como sei que minha letra é péssima e no quadro ouvi dizer que a letra sai pior ainda, pensei que sairia inelegível, só que para minha surpresa consegui ler o que escrevi, sendo que tenho que melhorar e muito. (A10)

Para começar sei que preciso melhorar minha caligrafia, pois até então não tinha percebido como minha letra é ilegível. (A09) 
[...] o desenho também poderia ter ficado melhor, sem tanta 'tortisse' se fosse feito mais lentamente. (A01)

IV - Gestão do Tempo: Nessa categoria trazemos para análise as afirmações dos licenciandos que destacam a gestão do tempo na mini-aula em suas declarações. Três depoentes ressaltam que a gestão do tempo na proposta deles foi falha, um ressalta que sua aula foi muito lenta e os demais que foi rápida. Em contrapartida, um depoente especifica que um ponto que considerou bom em sua atuação foi o intervalo de tempo que destinou para que seus alunos fictícios pudessem falar a respeito dos problemas matemáticos por ele planejados e apresentados na mini-aula. Configurando-se como sugestão para uma melhoria da prática docente em formação, dois sujeitos trazem reflexões que mencionam a necessidade de realizar um melhor planejamento do tempo destinado para a aula.

Da mesma forma, fiquei muito apegado ao tempo que tinha disponível e, com isso, minha preocupação ficou mais voltada em terminar a resolução do problema (que acabei nomeando demonstração) e não em como explicar a resolução à turma. (A13)

Tenho também que ter mais noção de tempo, pois não tinha percebido que fazia tanto tempo que estava apresentando a minha mini-aula. (A16)

Acredito que o tempo que deixei para que argumentassem sobre 0 problema foi suficiente, gostei muito disso. (A07)

V - Preparação da mini-aula: A preparação da mini-aula também foi um assunto abordado pelos licenciandos. Eles se reportaram às falhas e, entre elas, destacamos: casos em que o conceito matemático foi apresentado de um modo inapropriado; equívocos nos enunciados das questões aplicadas na mini-aula; notações matemáticas que estavam em desacordo com a idade da turma de alunos para que a aula foi proposta; a necessidade de preparação minuciosa da mini-aula; o aprofundamento no conteúdo matemático da aula. Mas também tivemos considerações positivas, como a manifestação de um dos licenciandos, quando afirma ter gostado da questão por ele escolhida, principalmente pela possibilidade de aprofundamento. Todavia, ele complementa "que não aproveitou a questão adequadamente em sua apresentação".

Da próxima vez, preciso preparar melhor minha aula. (A03 e A17)

Por isso, houve equívoco na construção do enunciado onde troquei a palavra "comprimento" por "largura" e vice-versa. Confundi-me algumas vezes na forma como deveria resolver o problema proposto. (A07)

Eu gostei da questão, pois ela permite a dedução da fórmula resolutiva de equações do segundo grau, que aprofunda o conteúdo matemático. Pena que não aproveitei isso em minha aula. (A07)

Por outro lado, poderia usar esse conteúdo (que eu acho muito rico) para abordar e aprofundar outras questões, a saber: relação entre 'divergência' e 'área infinita'. (A13)

[...] (utilizei) notações matemáticas incompatíveis com a 'idade' dos meus alunos. (A17) 
VI - Exposição do conteúdo matemático: Com relação a essa categoria, os depoentes assinalaram a respeito da organização na lousa; do respeito a uma sequência lógica entre a fala e aquilo que está escrito na lousa; a necessidade de justificar os procedimentos utilizados; as colocações faladas e escritas precisam estar claras e serem objetivas; indicam a utilização de desenhos como uma forma para facilitar a representação do conteúdo matemático.

[...] parti da formação de vetores a partir do ponto A e disse que depois explicaria o porquê, mas não retomei (A03).

Quando fui explicar a resolução do sistema, me atrapalhei [...] fui muito resumida, pois 'pulei' passos muito importantes, o que às vezes atrapalha o raciocínio do aluno (A06).

Em alguns momentos, eu deveria ter escrito no quadro todo o raciocínio, para que fique mais claro para o aluno o que eu estava fazendo. Creio que a dúvida que Abel teve foi exatamente por isso (A20).

[...] ao resolver esta equação do segundo grau, encontramos as soluções [...] encontramos os valores da incógnita que satisfazem a equação e, a partir desses valores, deve-se encontrar qual é a solução do problema (A01).

[...] preciso ter cuidado com a escrita matemática no quadro, ver se está correta, se os alunos entendem o que está sendo escrito, preocupações que me dou conta agora. (A05)

VII - O corpo: Nessa categoria, as unidades apresentam como característica em comum o fato de se referirem ao modo como o licenciando se comportou durante a miniaula. As críticas mencionadas se referem: às gesticulações, considerando-as exageradas; ao fato de ficar de costas para a turma; bem como o estranhamento de sua estatura e voz. Como sugestão, são indicadas as buscas por: naturalidade durante a aula; seriedade; aumento da movimentação pela sala de aula, "procurando não tampar com o corpo a lousa". Em contrapartida, tivemos ainda afirmações que consideraram o modo como seus gestos foram realizados durante a mini-aula um fator que contribui para o ensino de matemática de crianças.

[...] não gostei da minha comunicação gestual, como estava muito nervoso, achei-me bem estranho e confuso, deve ser por me tentar passar segurança, realmente não sei explicar. (A10)

[...] acho que vou continuar a ser inquieto, agora é estranho tentar sossegar. Penso, também, tirar proveito desse meu jeito de ser (principalmente nas séries iniciais do Ensino Fundamental), como as crianças também são inquietas eles podem ver uma similaridade. (A10)

Tenho que melhorar a minha postura perante uma sala de aula, agir com naturalidade. (A02)

Quanto à postura na atuação, acredito que devo me postar com mais seriedade frente à turma. (A01) 
Movimentar mais na sala pra não ficar estático, vique isso é importante. (A03)

Também tomar cuidado pra não tampar com o meu corpo o que estou escrevendo, quando possível. (A16)

VIII - Relação professor-aluno: Lembramos aqui, apesar de já termos destacado anteriormente, que esses alunos eram fictícios, ou seja, foi solicitado a eles que se reportassem à turma (seus colegas da licenciatura) como se eles fossem os alunos da 'suposta escola', considerando a faixa etária para quem estavam ministrando a mini-aula. E, ainda, foi solicitado aos colegas da licenciatura que fizessem ou respondessem perguntas (se fosse o caso) simulando serem os alunos daquele contexto fictício. Apesar de ser uma situação em simulação, ao construírem a autoscopia com base no vídeo da mini-aula os acadêmicos indicaram algumas falhas na maneira como se relacionaram com esses alunos (mesmo fictícios) e levantaram algumas qualidades que, segundo eles, podem contribuir com o processo de ensino e de aprendizagem em um contexto real de sala de aula.

No momento em que Abel (nome fictício) teve a ideia de resolver por 'chute', eu deveria ter perguntado como eu faria, para ter uma ideia melhor de como o Abel estava pensando. (A12)

Em determinada parte da aula a aluna Dulci fez um comentário e eu não dei a devida atenção, cometendoassim outra falha. (A20)

Outro ponto que ocorreu foi que apenas mostrei que sabia resolver o problema, ou seja, já comecei respondendo e em nenhum momento exercitei um diálogo com a turma, para que pudéssemos desenvolver o exercício juntos. (A23)

Na minha mini-aula, dei espaço para que os alunos participassem, pois gosto que haja interação entre alunos e professor, e entre eles mesmos. (A16)

\section{Conclusões}

Sabendo que partimos da proposta de conhecer as percepções dos licenciandos em matemática a respeito da realização de mini-aulas seguidas de uma tarefa que promovesse a autorreflexão da sua prática, denominada por autoscopia (SADALLA; LAROCCA; 2004), encerramos este artigo com algumas conclusões e, também, com alguns questionamentos que em momento oportuno serão retomados.

Nossa intenção não foi a de quantificar, mas acreditamos que este movimento também seria possível - o que nos propõem, em um futuro breve, retomar esses dados novamente, a frequência das falas nas categorias e em cada contexto.

Em função da busca por compreender quais eram as percepções dos acadêmicos em relação à atividade proposta, não assumimos categorias a priori, ou seja, não delimitamos o que queríamos verificar nas autoscopias, mas sim, após os procedimentos possibilitados pela Análise Textual Discursiva, buscamos por unidades de registro que apontassem para categorias emergentes, constituídas pelos próprios depoentes e não por balizamentos pensados de antemão. 
De forma sumarizada, podemos concluir que os acadêmicos, diante da proposta, observaram não somente o vídeo que os captura em certa prática, mas simularam, projetaram, relacionaram o ocorrido com um futuro próximo ou com situações já vivenciadas por eles. E dentro dessa perspectiva que denominamos como Contextos 01 e 02,os licenciandos teceram comentários, fizeram comparações e,o que nos chamou mais a atenção, avaliaram suas próprias práticas apontando-as como falhas, boas e enveredaramse por sugestões para rever aquilo que não os agradou. No Quadro 03, a seguir, buscamos representar de forma sintética diversos desses relatos, a fim de termos um mapeamento das percepções e reflexões por eles indicadas.

Quadro 03 - Síntese da análise das autoscopias

\begin{tabular}{|c|c|c|c|}
\hline & Procedimentos avaliados como falhos & $\begin{array}{c}\text { Procedimentos avaliados } \\
\text { como bons }\end{array}$ & $\begin{array}{c}\text { Sugestões de correção para } \\
\text { situações consideradas inadequadas }\end{array}$ \\
\hline 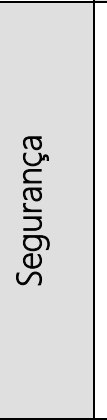 & $\begin{array}{ll}\text { - } & \text { Intimidou-se pelo público (amigos } \\
\text { - } & \text { da graduação). (A09) } \\
\text { - } & \text { Intimidou-se pelo fato de não ser } \\
\text { - } & \text { Falta de confiança. (A15) } \\
\text { - } & \text { Esquecimento (A06), pressa em } \\
\text { - } & \text { acabar a aula. (A01) } \\
\text { - } & \text { Nerda de concentração. (A15) } \\
\text { - } & \text { Medo. (A15) } \\
\end{array}$ & & $\begin{array}{l}\text { Relatos da necessidade de } \\
\text { sentirem-se mais seguros, } \\
\text { melhorando a conduta ou } \\
\text { superação do medo de dar } \\
\text { aulas. (A08, A15, A23) }\end{array}$ \\
\hline$\frac{\pi}{\frac{\pi}{\pi}}$ & $\begin{array}{ll}\text { - } & \text { Falta de clareza ao falar. (A07, } \\
& \text { A05, A10) } \\
\text { - } & \text { Vícios de linguagem. (A02, A12) } \\
\text { - } & \text { Tom de voz baixo. (A13, A20, } \\
& \text { A04) } \\
\text { - Uso de linguagem inapropriada à } \\
\text { idade dos alunos. (A17) }\end{array}$ & $\begin{array}{l}\text { - } \quad \text { Conceitua como boa a } \\
\text { sua fala durante a } \\
\text { mini-aula. }(A 05, A 12)\end{array}$ & $\begin{array}{ll}\text { - } & \text { Melhorar o vocabulário. (A02, } \\
& \text { A09, A08, A05) } \\
\text { - } & \text { Melhorar o modo de falar. } \\
& (\mathrm{A} 03, \mathrm{~A} 10, \mathrm{~A} 01) \\
\text { - } & \text { Reduzir os vícios de linguagem. } \\
& \text { (A16) } \\
\text { - } & \text { Falar com o tom de voz mais } \\
& \text { alto. (A13, A17) }\end{array}$ \\
\hline 莺 & $\begin{array}{l}\text { - } \text { O modo que usou a lousa pode } \\
\text { comprometer a compreensão dos } \\
\text { alunos. (A10, A05, A03, A19) } \\
\text { - Considera a letra feia. (A13, A02, } \\
\text { - A01, A06) } \\
\text { - Desenho torto. (A01) }\end{array}$ & $\begin{array}{ll}\text { - } & \text { Considera que a letra } \\
\text { não ficou tão ilegível } \\
\text { quanto imaginava. } \\
\text { (A10) } \\
\text { - Considera bom o } \\
\text { modo como organizou } \\
\text { a escrita no quadro. } \\
\text { (A05) }\end{array}$ & $\begin{array}{ll}\text { - } & \text { Treino de caligrafia na lousa. } \\
\text { (A02, A01, A10) } \\
\text { Melhorar a organização da } \\
\text { lousa. (A16) }\end{array}$ \\
\hline 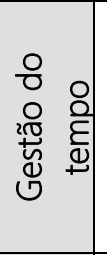 & $\begin{array}{l}\text { - Considera sua aula muito lenta e } \\
\text { demorada. (A02) } \\
\text { - Considera que sua aula foi muito } \\
\text { rápida. (A08, A13) }\end{array}$ & $\begin{array}{l}\text { - Considera bom o } \\
\text { tempo que destinou } \\
\text { para os alunos falarem } \\
\text { a respeito do } \\
\text { problema apresentado. } \\
\text { (A07) }\end{array}$ & $\begin{array}{l}\text { - Consideram a necessidade de } \\
\text { um planejamento melhor do } \\
\text { tempo da aula. (A16, A02) }\end{array}$ \\
\hline 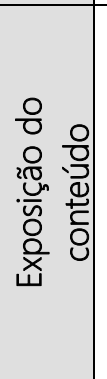 & $\begin{array}{l}\text { - } \text { Quebra de sequência lógica. } \\
\text { (A03) } \\
\text { Falta de justificativa de } \\
\text { procedimentos. (A08, A06) } \\
\text { - Confusões em como se expressar } \\
\text { durante a aula. (A01, A03, A05, } \\
\text { A01, A13) }\end{array}$ & $\begin{array}{ll}\text { - } & \text { Rigoroso com a } \\
\text { formalização da } \\
\text { matemática } \\
\text { apresentada. (A17) } \\
\text { Justificação da } \\
\text { utilidade do conteúdo } \\
\text { matemático } \\
\text { apresentado. (A12) }\end{array}$ & $\begin{array}{ll}\text { - } & \text { Expor o objetivo da aula. (A08) } \\
\text { - } & \text { Valer-se da utilização de } \\
& \text { desenhos para a aula. (A12) } \\
\text { - } & \text { Tomar cuidado com a } \\
& \text { coerência da escrita } \\
& \text { matemática. (A03) } \\
\text { - } & \text { Apresentar e justificar os } \\
& \text { procedimentos de realização } \\
\text { das resoluções.(A19, A20) }\end{array}$ \\
\hline
\end{tabular}




\begin{tabular}{|c|c|c|c|}
\hline 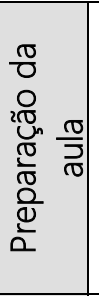 & $\begin{array}{l}\text { - } \quad \text { Conceituação matemática. (A03) } \\
\text { - } \quad \text { Elaboração de tarefas } \\
\text { - } \quad \text { matemáticas. (A07) } \\
\text { - } \quad \text { Falta de coerência do conteúdo } \\
\text { com a série a que se propôs dar a } \\
\text { aula. (A17) }\end{array}$ & $\begin{array}{l}\text { Gostou da questão } \\
\text { que escolheu para a } \\
\text { mini-aula, } \\
\text { especialmente a } \\
\text { possibilidade de } \\
\text { avanço. (A07) }\end{array}$ & $\begin{array}{l}\text { - } \quad \text { Necessidade de preparação de } \\
\text { - } \quad \text { Aprofunda melhor. (A17, A03) } \\
\text { matemático escolhido para a } \\
\text { aula. (A13) }\end{array}$ \\
\hline 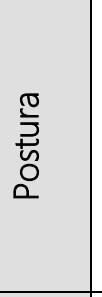 & $\begin{array}{ll}\text { - } & \text { Gesticulação exagerada. (A12, } \\
\text { A10) } \\
\text { - } \\
\text { Ficar de costas para a turma. } \\
\text { (A15, A17) } \\
\text { - Estranhamento de sua estatura } \\
\text { ou voz. (A17, A02) }\end{array}$ & $\begin{array}{l}\text { - } \quad \text { Considera a sua } \\
\text { gesticulação com as } \\
\text { mãos boa e pertinente } \\
\text { para o ensino de } \\
\text { matemática para as } \\
\text { crianças. (A10) }\end{array}$ & $\begin{array}{ll}\text { - } & \text { Busca por naturalidade. (A02) } \\
\text { - } & \text { Apresentar mais seriedade. } \\
\text { (A01) } & \text { Aumentar a movimentação na } \\
\text { - } & \text { sala. (A03) } \\
\text { - } & \text { Buscar não tampar o quadro } \\
& \text { com o corpo. (A16) } \\
\end{array}$ \\
\hline 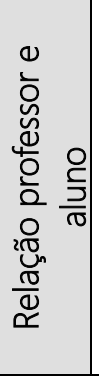 & $\begin{array}{ll}\text { - } & \text { Desprezo aos comentários dos } \\
\text { alunos. (A12, A20) } \\
\text { - } \\
\text { Falta de paciência para a } \\
\text { obtenção da resposta dos alunos. } \\
\text { (A12) } \\
\text { - Muito tempo sem falar com a } \\
\text { turma. (A17) } \\
\text { - Faltou trazer mais os alunos para } \\
\text { a aula. (A05, A23) }\end{array}$ & $\begin{array}{ll}- & \text { Oportunizou a } \\
& \text { participação dos } \\
& \text { alunos. (A16) }\end{array}$ & $\begin{array}{l}\text { - Instigar mais os alunos a } \\
\text { participarem da aula. (A20, } \\
\text { A01, A23, A13, A19, A08) } \\
\text { Utilização do material concreto. } \\
\text { (A03) }\end{array}$ \\
\hline
\end{tabular}

Fonte: Os autores.

Este quadro nos abre uma possibilidade: em momento posterior a esta comunicação e conclusão aqui apresentada, quantificar e transformar essas categorias emergentes em categorias a priori. Reaplicando a atividade em outras turmas da licenciatura e verificando a convergência das percepções. Fato que poderia nos conduzir à proposição de um trabalho em sala de aula - neste processo formativo em que esses acadêmicos se encontram focando essas temáticas / assuntos relativos à prática.

Muitas vezes para os formadores esses assuntos parecem recair em um mantra 'que era para já ser sabido', e pode passar despercebido em suas propostas de discussão e em seu planejamento, deixando de ser comentado ou estudado nas disciplinas que objetivam apresentar tais conteúdos sobre a prática de sala de aula.

Diante dessas constatações, podemos também concluir que a autoscopia, dentro da forma como transcorreu essa nossa proposta em investigação, pode ser considerada como uma oportunidade de desenvolvimento de autonomia docente, ou seja, um espaço que leva o futuro professor a pensar a respeito de sua prática, avaliar o que foi desenvolvido e se mobilizar refletindo sobre uma prática outra que viesse melhorar os problemas identificados. Aproximando essas considerações do que Schön (1997, p.89) denomina por "mundo virtual", isto é, "[...] qualquer cenário que representa o mundo real - um mundo da prática - e que nos permite fazer experiências, cometer erros, tomar consciência dos nossos erros, e tentar de novo, de outra maneira".

Todavia, cabe ressaltar que a mini-aula não é uma representação completa da sala de aula, há muitos fatores relacionados: a instância institucional;a presença de alunos na faixa etária da série a que o licenciado se propôs a ministrar sua aula;e diversos outros vieses sociais, culturais e históricos relativos à escola propriamente dita. Porém, é um momento em que o futuro professor se lança nas práticas educativas, podendo errar quantas vezes forem necessárias para a construção do seu aprendizado, sem temer as consequências reais de seus desajustes, deslizes e erros. 
Por fim, podemos assumir que esta tarefa proporcionou uma oportunidade de desenvolvimento da autonomia, em que o licenciando pôde se 'ver em ação' e posicionarse em relação aos problemas por ele identificados.

\section{Referências}

ALARCÃO, I. (Org.). Formação reflexiva de professores: estratégias de supervisão. Porto: Porto Editora, 1996.

BARDIN, L.Análise de conteúdo. Lisboa: Ediç̧̃es 70, 1977, 3. ed., 2004.

CARVALHO, D. F. O estágio curricular supervisionado e a decisão dos licenciandos em querer ser professor de matemática. 2012. 141f. Dissertação (Mestrado em Ensino e Ciências e Educação Matemática) - Universidade Estadual de Londrina, Londrina, 2012.

OLIVEIRA, M. K. de. Vygotsky: aprendizado e desenvolvimento - um processo sócio-histórico. São Paulo: Scipione, 1993.

MORAES, R.; GALIAZZI, M. do C.Análise textual discursiva. Ijuí: Editora Unijuí, 2011.

SADALLA, A. M. F. A.; LAROCCA, P. Autoscopia: um procedimento de pesquisa e de formação. Educação e Pesquisa, São Paulo, v.30, n.3, p.419-433, set./dez. 2004.

SCHÖN, D. A. Educating the reflective practitioner. San Francisco: Jossey-bass, 1987. 